\title{
OS LIMITES SEMÂNTICOS DE HUMPTY DUMPTY
}

Luciano Amaral Oliveira*

RESUMO: Humpty Dumpty é um personagem de "Alice no País do Espelho", de Lewis Carroll. Seu comportamento rebelde em relação ao significado das palavras é o ponto de partida para se problematizar os limites semânticos impostos aos leitores e aos falantes-ouvintes de uma língua natural. Dois livros de Umberto Eco sobre essa questão servem de base para se mostrar quais são esses limites.

PALAVRAS-CHAVE: Interpretação, Leitor, Significado Literal.

ABSTRACT: Humpty Dumpty is a character in "Alice through the Looking Glass", by Lewis Carroll. His rebel-like behavior in relation to the meaning of words is the starting point of the problematization of the semantic limits of readers and speakerhearers of a natural language. Two books by Umberto Eco on this matter serve as a basis for the showing what those limits are.

KEY-WORDS: Interpretation, Reader, Literal Meaning. 
*Prof. Dr. da Universidade Estadual de Feira de Santana - UEFS Pra começo de conversa...

"Você terá a glória!"

"Eu não sei o que você quer dizer com 'glória” - retrucou Alice.

Humpty Dumpty sorriu com desdém - "É claro que você não sabe - até que eu diga a você. Eu quis dizer que você terá um belo e incontestável argumento!"

"Mas 'glória' não significa 'um belo e incontestável argumento"” - contestou Alice.

"Quando eu uso uma palavra" - disse Humpty Dumpty em um tom bastante zombeteiro - "ela significa exatamente o que eu quero que ela signifique, nem mais nem menos."

"A questão é" - disse Alice - "se você pode fazer com que as palavras signifiquem tantas coisas diferentes". ${ }^{1}$

(CARROLL, 2000, tradução minha)

Ovo simpático e rebelde é esse tal de Humpty Dumpty. Seu comportamento pós-moderno confunde a cabeça da ingênua Alice, leitora moderna de um país de espelhos desconstruídos. Afinal, como é que Humpty Dumpty se acha com o poder de dar a uma palavra o significado que ele quiser? Alice parece não perceber que, no mundo maravilhoso e espelhado vislumbrado pelo matemático Lewis Carroll, Humpty Dumpty tem esse poder. Até mesmo ela, Alice, poderia ter esse poder se quisesse.

Entretanto, no mundo positivistamente real em que os leitores carrollianos (e drummondianos, derridianos, etc.) se encontram e funcionam socialmente, os leitores e falantes-ouvintes podem dar às palavras os significados que eles quiserem? Eles se comportam como Humpty Dumpty ou eles obedecem a limites semânticos nos atos da interpretação e do uso das palavras?

Algumas pessoas responderiam prontamente que o leitor e o falante-ouvinte não se comportam como o ovo em questão. E, provavelmente, elas não abririam mão de evocarem a obviedade 
da resposta. Mas o óbvio afirmado e o acordo tácito inconteste não bastam à academia. A obviedade é tão relativa quanto a dicotomia certo/errado. O que é óbvio para muitos desconstrutivistas, por exemplo, parece absurdo para quem não compartilha das crenças desconstrutivistas. Por outro lado, a obviedade da existência do significado literal é execrada por desconstrutivistas de plantão.

Assim, é necessário que se busquem evidências para os limites semânticos impostos ao leitor e ao falante-ouvinte. E é exatamente a isso que este ensaio se propõe: mostrar que existem limites semânticos que são impostos aos leitores e aos falantes-ouvintes (note-se que o uso da voz passiva aqui não foi por acaso). Portanto, pra começo de conversa, que uma coisa fique clara: o leitor não se comporta como Humpty Dumpty, seja esse leitor moderno ou pós-moderno. Os limites semânticos impostos a esse leitor são o que interessa a este ensaio.

\section{Então, indo ao que interessa...}

Em 1992, um vendaval francês sacudiu os alicerces dos filósofos da conservadora Universidade de Cambridge. Eram as idéias desconstrutivistas construídas por Jacques Derrida na década de 1960 (COLLINS; MAYBLIN, 1997). Além de aumentar a fogueira de vaidades acadêmicas e de provocar reflexões filosóficas na terra da Sua Majestade, os ventos derridianos sopraram nos quatro cantos do mundo, influenciando não apenas filósofos, mas também teóricos da tradução e críticos literários.

De acordo com Jeff Collins e Bill Mayblin (ibidem, p. 16), o trabalho de Derrida é dominado pela idéia de um vírus que introduz desordem na comunicação e que não é vivo nem morto. Isso implica as idéias de indeterminação e de instabilidade, que foram apropriadas por teóricos da tradução e por críticos literários. Stephan Collini $(2001$, p. 9) deixa isso bem claro, quando comenta a respeito de Umberto Eco:

Tendo sido uma das pessoas mais influentes a chamar 
a atenção, nos anos 60 e 70, para o papel do leitor no processo de "produzir" significado, mostrou, em sua obra mais recente, apreensão quanto à maneira pela qual algumas das principais correntes do pensamento crítico contemporâneo, em particular aquele tipo de crítica americana inspirada em Derrida, autodenominada "Desconstrução" e associada sobretudo ao trabalho de Paul de Man e J. Hillis Miller, parecem dar licença ao leitor de produzir um fluxo ilimitado e incontrolável de "leituras".

Com efeito, os teóricos que defendem o poder exclusivo do leitor para criar significados fazem questão de enfatizar a natureza indeterminada e instável do significado, negando veementemente a existência dos significados literais, i.e. estáveis, no texto. Por exemplo, Rosemary Arrojo e Kanavillil Rajagopalan (1992, p. p. 47), teóricos pós-estruturalistas da tradução, contestam o significado literal, que é "tradicionalmente associado a uma estabilidade de significado, inerente à palavra ou ao enunciado, que supostamente preserva a linguagem da interferência de quaisquer contextos e/ou interpretações.” As palavras de Arrojo e Rajagopalan merecem alguns comentários.

A associação entre estabilidade e literalidade procede. $\mathrm{O}$ significado literal é entendido como sendo um significado estável em uma comunidade lingüística. Entretanto, é necessário cuidado no uso do termo "inerente". O fato de um significado ser estável não significa que uma determinada palavra tenha um significado que lhe seja inerente, fixo e imutável. Se isso fosse verdade, não haveria mudanças semânticas e expressões idiomáticas. A suposição manifestada por Arrojo e Rajagopalan, i.e., a de que o significado literal, estável, "preserva a linguagem da interferência de quaisquer contextos e/ou interpretações”, é improcedente. Há aí um radicalismo no argumento: força-se o atrelamento de “inerente" a "literal" para sustentar as idéias de indeterminação e de instabilidade do significado.

Stanley Fish (2000, p. 268), crítico literário de grande influência 
nos anos 1980 e 1990, também se apropria dessas duas idéias para defender o poder do leitor e negar o significado literal:

[...] a língua não tem uma forma independente do contexto, mas, como a língua é encontrada apenas em contextos e nunca no abstrato, ela sempre tem uma forma, embora nem sempre seja a mesma. O problema com essa formulação é que, para muitas pessoas, a determinação é inseparável da estabilidade: a razão pela qual nós podemos especificar o significado de um texto é porque um texto e seus significados nunca mudam. 2 (tradução minha)

Ora, defender-se a estabilidade do significado, na figura do significado literal, não significa defender a idéia, indefensável, de que um texto e seus significados nunca mudem. Os textos de Wilhelm Reich foram considerados subversivos e perigosos pela democracia norte-americana nos anos 1950, mas, nos últimos vinte anos, transformaram-se em importantes fontes de pesquisa para a elaboração de terapias corporais nos Estados Unidos, como a Bioenergética, de Alexander Lowen. É importante, sim, que se dê ao leitor o seu devido valor: ele não é um sujeito passivo que busca no texto o significado que o autor colocou ali. Contudo, é necessário reconheer-se que o leitor produz significados com base naquilo que o autor colocou no texto, com base nos significados literais do texto.

$\mathrm{Na}$ verdade, o debate em torno da determinação e da estabilidade do significado está inserido em uma questão maior, chamada por Eco (2001, p. 27) de "dialética entre os direitos do texto e os direitos de seus intérpretes". As idéias de indeterminação e de instabilidade, originadas nos pensamentos de Derrida, foram apropriadas pelos defensores do poder do leitor com o objetivo de minar os argumentos a favor do poder do texto. Segundo esses defensores, se o significado é indeterminado e instável, ele não pode estar no texto. E se o significado não está no texto, o leitor é que o produz. 
O problema da argumentação de muitos defensores do poder do leitor é o radicalismo. Arrojo (2002), por exemplo, chega a afirmar que o texto não tem conteúdo até o momento em que é interpretado pelo leitor, sendo seguida por inúmeros teóricos pós-estruturalistas da tradução no Brasil. Eco $(2001$, p. 27) faz uma crítica elegante a radicalismos desse tipo ao afirmar: "Tenho a impressão de que, no decorrer das últimas décadas, os direitos dos intérpretes foram exagerados".

Eco está certo. Afinal, como é possível negar a existência de significados no texto, dando-se o poder de criação de significados exclusivamente ao leitor? E se o leitor cria significados por meio da interpretação que impõe ao texto, há limites para essa criação? O que o impede de se comportar como Humpty Dumpty? E se o texto não tem conteúdo, não possui significados antes da leitura, o que o leitor interpreta?

Os defensores radicais do poder do leitor se vêem em apuros com essas perguntas. Eles admitem que o leitor não se comporta como Humpty Dumpty. Admitem que há limites para a interpretação. Mas não conseguem dizer quais são esses limites nem responder à pergunta sobre o objeto da interpretação.

Segundo Eco (ibidem, p. 28), "[...] como Todorov sugeriu maliciosamente (citando Lichtenberg a propósito de Boeheme), um texto é apenas um piquenique em que o autor entra com as palavras e os leitores com o sentido". Eco (ibidem, p. 28) acrescenta: "Mesmo que isso fosse verdade, as palavras trazidas pelo autor são um conjunto um tanto embaraçoso de evidências materiais que o leitor não pode deixar passar em silencio, nem em barulho". Entretanto, apesar das evidências materiais e da dificuldade insuperável de dizer qual é o objeto da interpretação (já que, alega-se, o texto não possui significados), os defensores do poder do leitor não admitem a existência do significado literal. Resta a eles, então, radicalizar ao extremo, como faz Arrojo (1992, p. 39):

[...] para a reflexão desconstrutivista, o significado não se encontra preservado no texto, nem na redoma supostamente protetora das intenções conscientes de 
seu autor, tampouco nasce dos caprichos individualistas do leitor rebelde; o significado se encontra, sim, na trama das convenções que determinam, inclusive, o perfil, os desejos, as circunstâncias e os limites do próprio leitor.

Observe-se a saída de Arrojo: o objeto da interpretação, o leitor e o significado são todos produtos das convenções. Em outras palavras, é a comunidade que determina tudo. De onde Arrojo tirou essa posição tão radical? Do pensamento de Fish (2000), que elimina o texto e o leitor "de um só golpe" e para quem as comunidades interpretativas determinam tudo: autor, leitor, texto, significados. Nas palavras de Fish (2000, p. 14):

[...] são as comunidades interpretativas, ao invés do texto ou do leitor, que produzem significados e que são responsáveis pela emergência de traços formais. Comunidades interpretativas são formadas por aqueles que compartilham estratégias interpretativas não para a leitura mas para a escrita de textos, para a constituição de suas propriedades. Em outras palavras, essas estratégias existem anteriormente ao ato de leitura e, portanto, determinam a forma do que é lido ao invés do contrário, como geralmente se presume. (tradução minha) ${ }^{3}$

Incapaz de manter a sua posição a respeito do poder do leitor de criação de significados sem responder às perguntas sobre o objeto da interpretação e sobre os limites da interpretação, Fish apela para o conceito de comunidades interpretativas, que passou a ser adotado por outros teóricos. Ironicamente, ao adotarem esse conceito, eles devem admitir que tudo é anterior à leitura, inclusive o significado. Adotam, também, uma postura monista radical, segundo o crítico literário Jonathan Culler (1997, p. 84):

O que vemos nas manobras de Fish são momentos de uma luta geral entre o monismo da teoria e o dualismo 
da narrativa. As teorias de leitura demonstram a impossibilidade de estabelecerem-se distinções bem fundamentadas entre o fato e a interpretação, entre o que pode ser lido no texto e o que lhe é adicionado pela leitura, ou entre o texto e o leitor, e assim conduzem a um monismo. Tudo é constituído pela interpretação - tanto que Fish admite não poder responder à seguinte pergunta: Atos interpretativos são interpretações do quê? [...] Histórias de leituras, no entanto, não deixam essa pergunta sem resposta. É preciso que haja sempre dualismos: um intérprete e algo a interpretar, um sujeito e um objeto, um ator e algo sobre o que ele age ou que age sobre ele.

Do exposto até aqui, alguns pontos ficam claros. Em primeiro lugar, teóricos têm debatido a respeito da criação de significado. Alguns defendem a existência de significados no texto antes da leitura, i.e., a existência de significados literais, sem negar o poder de criação de significados por parte do leitor. Outros negam o significado literal e conferem ao leitor o poder de criação de significados, que inexistem no texto até o momento em que é interpretado pelo leitor. Em segundo lugar, os defensores radicais do poder do leitor não conseguem responder à pergunta sobre o que o leitor interpreta se não há significados no texto antes da leitura. Em terceiro lugar, todos os teóricos envolvidos no debate admitem que há limites da interpretação, sendo que os defensores radicais do poder do leitor não esclarecem quais são esses limites. Finalmente, os defensores radicais do poder do leitor adotam o conceito fishiano de comunidades interpretativas, assumindo uma postura monista e escapando das perguntas sobre o objeto da interpretação e sobre os limites semânticos do leitor, que não se comporta como Humpty Dumpty.

Finalizando...

Humpty Dumpty não tem limites semânticos. Ele faz 
o que quiser. Tem o poder para isso. Felizmente, para o bem da comunicação e da convivência social, o leitor e o falante-ouvinte têm limites semânticos que o impedem de produzir significados caóticos. Isso é evidenciado na admissão de todos os teóricos envolvidos no debate em torno da criação de significados: há limites para a interpretação. E por quê? Porque os textos e as palavras possuem significados literais, significados a priori, significados estáveis.

É importante deixar claro o que são significados literais, estáveis. Todo falante-ouvinte de uma língua natural, ao adquirir essa língua, adquire um conjunto de palavras que fazem parte do léxico dessa língua. Ao adquirirem essas palavras, os falantesouvintes adquirem também os significados dessas palavras, a elas atrelados pela comunidade lingüística em um determinado momento da história. Note-se também que, ao longo da história dessa língua, a comunidade pode modificar os significados das palavras.

Assim, as palavras sempre possuem significados anteriormente ao uso que se faz delas. $\mathrm{O}$ falante-ouvinte ou o leitor, ao usar uma palavra, já a recebe com um significado que a ela foi atrelada pela sua comunidade lingüística. Isso não significa, entretanto, que o leitor e o falante-ouvinte não possa acrescentar significações ao significado literal. Os falantes-ouvintes e os leitores e escritores compartilham esses significados, mas cada um os interpreta a sua maneira, de acordo com sua história pessoal e com o contexto em que se encontra.

São esses significados que o leitor interpreta no texto. Os significados literais são os limites da interpretação do leitor. São os significados literais que impedem o leitor de se comportar como Humpty Dumpty. Por exemplo, imagine-se que um poema de um certo poeta apresenta a palavra "banana". Cada leitor pode interpretar "banana" de uma forma diferente da outra, mas todos partirão do significado literal de "banana" para realizar suas interpretações, qual seja, uma fruta com tais e tais características prototípicas. É muito pouco provável que alguém parta do 
pressuposto de que "banana" significa "ornitorrinco maluco sem pernas”, como Humpty Dumpty poderia fazer.

Eco (2000, p. 10-11) lembra um episódio interessante que ocorreu em 1984. Derrida enviou a Eco uma carta informando que estava criando, junto com uns amigos, um Collège International de Philosophie e pediu-lhe uma carta de apoio. Eco comenta que partiu de alguns pressupostos para interpretar a carta de Derrida, como, por exemplo, o pressuposto de que ele estava dizendo a verdade. Eco comenta o seguinte a respeito da interpretação que fez :

É óbvio que a carta de Derrida teria podido assumir para mim outros significados, estimulando-me a fazer suspeitosas conjecturas sobre o que ele queria "dar-me a entender". Mas qualquer outra inferência interpretativa (por mais paranóica que fosse) ter-se-ia baseado no reconhecimento do primeiro nível de significado da mensagem, literal.

É exatamente esse primeiro nível de significado que Humpty Dumpty não reconhece ao usar a palavra "glória" na sua conversa com Alice, que protesta por essa rebeldia semântica. Uma rebeldia que o pós-modernismo gostaria de ver encarnada no seu leitor, mas que não pode defender. Terry Eagleton (1998, p. 35) lembra que o pós-modernismo:

Ao mesmo tempo libertário e determinista, sonha com um sujeito ivre de limitaçoes, desizando teito um desvairado de uma posição a outra, e sustenta simultaneamente que o sujeito é o mero efeito do conjunto de forças que o constituem.

Os limites semânticos de Humpty Dumpty são aqueles que ele quiser ter. Já os limites semânticos do leitor, moderno ou pósmoderno, desconstrutivista ou desconstruído, são os significados literais. Desses limites, ninguém escapa. Só Humpty Dumpty. 


\section{NOTAS}

${ }^{1} c f$. trecho original:

"There's glory for you!"

"I don't know what you mean by 'glory'," Alice said.

Humpty Dumpty smiled contemptuously. "Of course you don't - till I tell you. I meant 'there's a nice knock-down argument for you!"”

"But 'glory' doesn't mean 'a nice knock-down argument'," Alice objected.

"When Iuse a word," Humpty Dumpty said in rather a scornful ton,

"it means just what I choose it to mean - neither more nor less." "The question is," said Alice, "whether you canmake words mean so many different things.

${ }^{2} c f$. o trecho original: [...] language does not have a shape independent of context, but since language is only encountered in contexts and never in the abstract, it always has a shape, although it is not always the same one. The problem with this formulation is that for many people determinancy is inseparable from stability: the reason that we can specify the meaning of a text is because a text and its meanings never change.

${ }^{3} c f$. o trecho original: [...] it is interpretive communities, rather than either the text or the reader, that produce meanings and are responsible for the emergence of formal features. Interpretive communities are made up of those who share interpretive strategies not for reading but for writing texts, for constituting their properties. In other words these strategies exist prior to the act of reading and therefore determine the shape of what is read 
rather than, as is usually assumed, the other way around.

\section{REFERÊNCIAS}

ARROJO, Rosemary. A desconstrução do logocentrismo e a origem do significado. In: ARROJO, ROSEMARY. (Org.) O signo descontruído - implicações para a tradução, a leitura e o ensino. Campinas: Pontes Editores, p. 35-39, 1992.

. Oficina de tradução: a teoria na prática. 4. ed. 3. imp. São Paulo: Ática, p. 85, 2002.

; RAJAGOPALAN, Kanavillil. A noção de literalidade: metáfora primordial. In: ___ (Org.) O signo descontruído - implicações para a tradução, a leitura e o ensino. Campinas: Pontes Editores, p. 47-54, 1992.

CARROLL, Lewis. Alice through the looking glass. Disponível em: < http://www.cs.indiana.edu/metastuff/looking/ch6.html. gz > . Acessado em: 13/03/2004.

COLLINI, Stephan. Introdução: interpretação terminável e interminável. In: ECO, Umberto. Interpretação e 
superinterpretação. Tradução Editora Martins Fontes. São Paulo: Martins Fontes,p.1-25, 2001. Título original: Interpretation and overinterpretation.

COLLINS, Jeff; MAYBLIN, Bill. Introducing Derrida. reimp. Grã-Bretanha: Totem, 1997.

CULLER, Jonathan. Sobre a desconstrução: teoria e crítica do pós-estruturalismo. Tradução Patrícia Burrowes. Rio de Janeiro: Rosa dos Tempos, 1997. Título original: On deconstruction: theory and criticism after structuralism.

EAGLETON, Terry. As ilusões do pós-modernismo. Tradução Elizabeth Barbosa. Rio de Janeiro: Jorge Zahar Editor, 1998. Título original: The illusions of postmodernism.

ECO, Umberto. Os limites da interpretação. Tradução Pérola de Carvalho. São Paulo: Perspectiva, 2000. Título original: I limiti 
179 